\title{
7
}

\section{Sensitive Detection of Cereal Fractions that Are Toxic to Coeliac Disease Patients, Using Monoclonal Antibodies to a Main Immunogenic Gluten Peptide}

\author{
Carolina Sousa, Ana Real, $\mathrm{M}^{\mathrm{a}}$ de Lourdes Moreno and Isabel Comino \\ Department of Microbiology and Parasitology, \\ Faculty of Pharmacy, University of Seville, Seville,
}

Spain

\section{Introduction}

Coeliac disease $(C D)$ is a common autoimmune disorder that has genetic, environmental, and immunological components. Though under-diagnosed, it is one of the most prevalent chronic gastrointestinal diseases in humans, and exhibits unusually large clinical, histological, immunological, and genetic heterogeneity (Alaedini \& Green, 2005; Sollid \& Khosla, 2005). The clinical spectrum of CD has been expanded in recent years, with the identification of asymptomatic patients, patients with minimal symptoms (the most difficult to detect), and patients with extra-intestinal symptoms (Sollid \& Khosla, 2005). Regardless of symptomatic presentation, the active disease in virtually all $\mathrm{CD}$ patients requires dietary exposure to a common environmental antigen, gluten. The ingestion of gluten proteins contained in wheat, barley, and rye, and in some cases oats (Arentz-Hansen et al., 2004; Comino et al., 2011), leads to characteristic inflammation, villous atrophy, and crypt hyperplasia in the CD patient's upper small intestine.

Gluten is a complex mixture of polypeptides. The main immunogenic peptides of gluten belong to a family of closely related proline- and glutamine-rich proteins called prolamines (15\% proline and 35\% glutamine residues). Gliadin, hordein, secalin, and avenin are the prolamines of wheat, barley, rye, and oats, respectively (Sollid \& Khosla, 2005).

$\mathrm{CD}$ is triggered by peptides that result from the fragmentation of prolamines, and are not digested by human proteases because the high proline and glutamine content prevents complete proteolysis by gastric and pancreatic enzymes, and long oligopeptides that are toxic to coeliac sprue patients build up in the small intestine (Sollid \& Khosla, 2005). In vitro and in vivo studies in rats and humans have demonstrated that a 33-mer peptide from $\alpha$ gliadin is not digestible by gastric, pancreatic, and intestinal brush-border membrane endoproteases (Shan et al., 2002). This and similar peptides have been identified as the principal contributors to gluten immunotoxicity.

At present, treatment with a gluten-free diet (GFD) is the only available therapy for CD patients. However, it is not easy to maintain a diet with zero gluten content because gluten 
contamination of food is commonplace (Collin et al., 2004). Even products specifically targeted at dietary treatment of $\mathrm{CD}$ may contain tiny amounts of gluten proteins, either because of the cross-contamination of originally gluten-free cereals during their milling, storage, and manipulation, or because of the presence of wheat starch as a major ingredient. Gluten is a common ingredient in the human diet; after sugar, it is perhaps the second most widespread food substance in Western civilization. Since about $10 \%$ of gluten seems to be made up of potentially toxic gliadin peptides (Sollid \& Khosla, 2005), the characterization and quantification of the toxic peptides of the gluten in foodstuffs is crucial to avoid coeliac damage and enable monitoring of their enzymatic detoxification.

\section{Gluten testing}

\subsection{Antibodies testing for gluten-free foods}

A standardized method of analysis is needed to quantitatively determine the gluten content of food and provide the basis for enforcing regulations regarding use of the term "glutenfree" in food labelling. People with coeliac disease should feel confident that foods labelled "gluten-free" have been assessed for gluten using the same "best available" methodology. According to the Codex Alimentarius, only food with a gluten content under $20 \mathrm{ppm}$ can be considered gluten-free. Food containing between 20 ppm and 100 ppm of gluten is considered to be very low in gluten content according to EU regulations, but there is no full agreement among countries about the term "gluten-free food". Unfortunately, there is not a well-defined correlation between the amount of gluten ingested and the severity of clinical symptoms, which makes finding a threshold value difficult. Various antibodies $(\mathrm{Ab})$ have been raised against different gliadin epitopes. The anti $\omega$-gliadin $A b$ is used in a sandwich format that was approved as an official method by the AOAC (Association of Official Agricultural Chemists; Skerritt \& Hill, 1991). However, the content of $\omega$-gliadin in wheat varies significantly, from $6 \%$ to $20 \%$, and this method cannot accurately detect and quantify barley prolamines (Thompson \& Mendez, 2008). The $\omega$-gliadin (Skerritt) ELISA was developed in 1991 and was considered a first reference assay. Subsequent assays have improved on some of the important limitations of the techniques based on the Skerritt antibody ELISA. Other antibodies were raised against different epitopes of $\alpha$-gliadin, such as PN3 (residues 31-49) for the toxic 19-mer peptides (Ellis et al., 1998), CDC5 (residues 5675; Nassef et al., 2008), Abs against T-cell stimulatory peptides present in gluten (Mitea et al., 2008), and R5, which recognized highly repeated peptide sequences present in wheat, barley, and rye grains (Valdés et al., 2003). The sandwich R5 ELISA was endorsed as a type I method by the Codex Committee on Methods of Analysis and Sampling (Codex Alimentarius Commission. Report of the $27^{\text {th }}$ session of the Codex Committee on methods of analysis and sampling 2006, ALINORM 06/29/23) for gluten determination. One criticism is that it overestimates barley hordein (Thompson \& Méndez, 2008). It is also unable to accurately quantify hydrolyzed gluten.

\subsection{Antibodies to toxic gluten peptides}

Recent advances in the coeliac field strongly recommend updating the concept of "gluten detection" to "potential relative immunotoxicity of gluten" for the safety of coeliac consumers of food. Two monoclonal antibodies (moAbs), A1 and G12, were raised against 
the immunodominant peptide 33-mer (LQLQPFPQPQLPYPQPQLPYPQPQLPYP QPQPF, residues 57 to 89; Morón et al., 2008a).

\subsubsection{Detection of gliadin immunogenic peptide by anti-33-mer moAbs}

The 33-mer peptide from $\alpha-2$ gliadin is a principal contributor to gluten immunotoxicity (Shan et al., 2002). Thus the production of moAbs against this toxic gluten peptide could be of great importance in both research and diagnosis. We obtained moAbs against the 33-mer peptide (A1 and G12 moAbs) (Morón et al., 2008a). To test the relative sensitivity of each moAb for the 33-mer peptide, we immobilized different concentrations of the C-LYTAG-33mer polypeptide, and detected with A1 and G12 moAbs in an indirect ELISA. The affinity of each moAb for the antigen was quantified by calculation of the concentration of the antigen giving a 50\% reduction of the peak signal in the ELISA (IC50). The sensitivity of the G12 $\mathrm{moAb}$ for the toxic 33-mer peptide was about eight times higher than that of A1 (Figure 1A). To test for moAb specificity, we studied the cross-reactivity (CR) values of these moAbs against commercial gliadin, also by indirect ELISA. The G12 moAb presented an IC50 of almost double that obtained with the A1 moAb, suggesting that A1 had broader reactivity with gliadin epitopes than did G12, which is more specific for the 33-mer (Figure 1B).
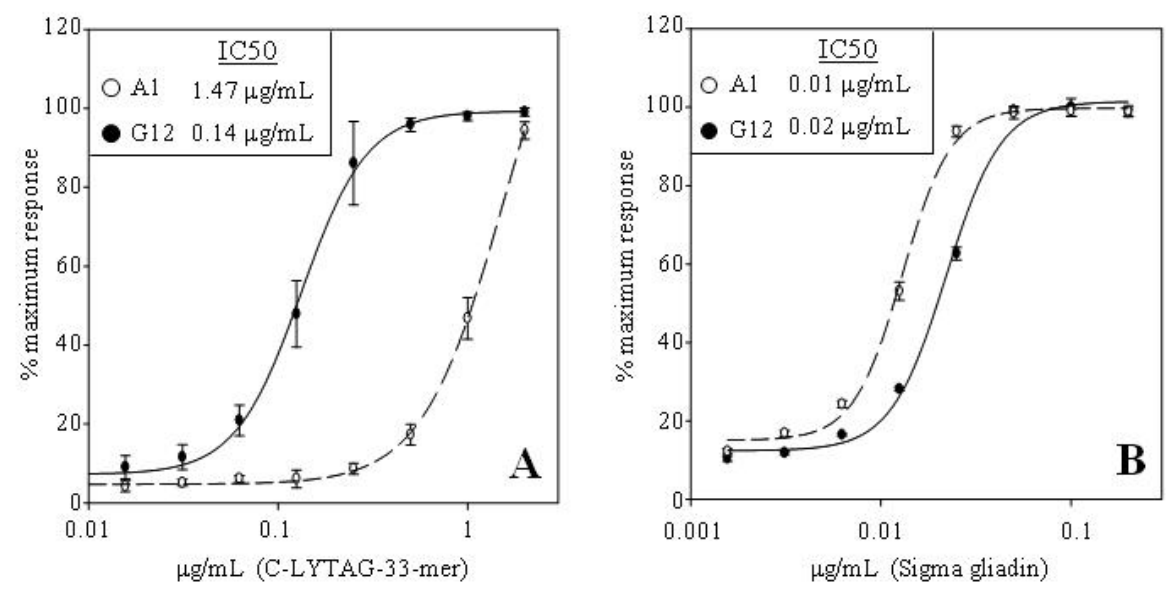

Fig. 1. Standard curve of the detection of C-LYTAG-33-mer polypeptide (A) and Sigma gliadin (B) by indirect ELISA using G12 (black) and A1 (white) moAbs. Each point of the curve represents the mean \pm standard deviation of $n=4$ assays. IC50 values of the moAbs to the two antigens are indicated.

\subsubsection{Characterization of A1 and G12 moAb sensitivity for coeliac-toxic cereals}

We investigated whether the G12/A1 moAbs were able to detect the presence of gliadin 33mer-related epitopes in prolamines from various cereals (Morón et al., 2008a; 2008b). To obtain quantitative data on the capacity of these antibodies to detect coeliac-toxic prolamines, we performed an indirect ELISA with samples of wheat, barley, rye, oats, rice, and maize (Figure 2). The assay proved to be highly specific for wheat, rye, and barley, as no 
signal was observed in samples containing prolamines from rice or maize (Figure 2). The G12 and A1 moAbs detected oats with lower sensitivity, indicating that there are peptides in avenin with sequence similarity to the 33-mer. This is consistent with the identification of proline- and glutamine-rich epitopes in avenins that are toxic in some CD patients (ArentzHansen et al., 2004). The lower sensitivity for oat avenins may be due to the lower proportion of oat-flour protein content consisting of prolamines relative to the proportion of gliadins, hordeins, or secalins in their respective grains.

The A1 moAb was clearly more sensitive than the G12 moAb for the detection of the prolamine fractions from wheat, barley, rye, and oats. Although they were targeted at the toxic 33-mer peptide of wheat gliadin, both moAbs were more sensitive for barley than for wheat (Figure 2), with the affinity for barley of the A1 moAb being almost three-fold higher than that of the G12. The A1 was also more sensitive for the prolamines of rye than for those of wheat.

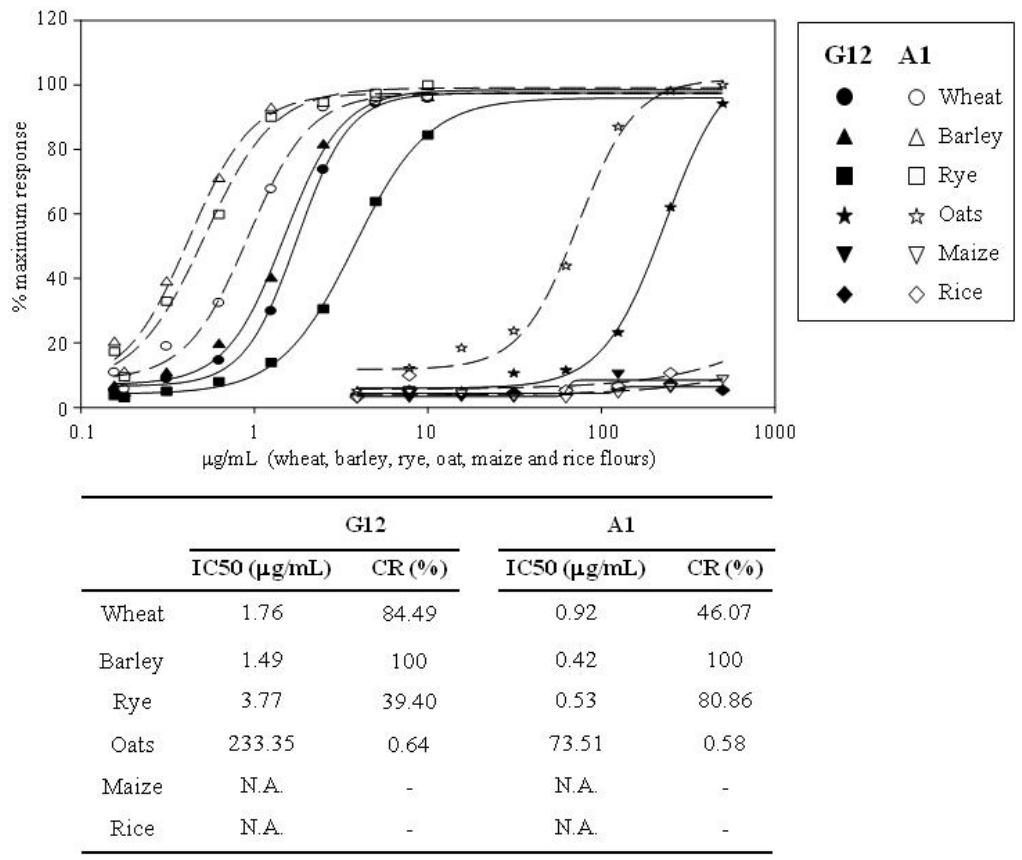

Fig. 2. Comparative reactivity of prolamines from wheat, barley, rye, oats, maize, and rice from indirect ELISAs using G12 (black) and A1 (white) moAbs. Each point of the curve shows the mean of $n=3$ assays. IC50 and $C R$ values of the moAbs to prolamines are indicated. N.A.: Not applicable.

\subsubsection{Development of a competitive ELISA assay using the anti-gliadin 33-mer moAbs}

The preparation of many foodstuffs involves heating or enzymatic processes that may partially hydrolyze or deamidate gluten. As a result, the quantity of gluten extracted from 
foodstuffs processed by heat or fermentation may be underestimated by indirect or sandwich ELISA. We therefore developed a competitive ELISA method using the G12 moAb. The result was a highly sensitive competitive assay with a limit of detection of 0.44 $\mathrm{ng} / \mathrm{mL}$ and a limit of quantification of $3.95 \mathrm{ng} / \mathrm{mL}$. The gliadin concentration giving a $50 \%$ reduction in the maximum signal (i.e., IC50) in the standard curve of the competitive ELISA was determined to be $26.92 \mathrm{ng} / \mathrm{mL}$. The repeatability and reproducibility of the method were calculated from various standard curves performed on the same ELISA plate (intraassay) and on different ELISA plates (inter-assay), respectively. For the standards situated between $25 \mathrm{ng}$ gliadin/ $\mathrm{mL}$ and $1.56 \mathrm{ng}$ gliadin/ $\mathrm{mL}$, the intra-assay was $1.38-3.75 \%$, and the inter-assay was $1.65-10.30 \%$ for the same standards. To determine whether the competitive assay was able to detect small fragments originated by gliadin digestion, we analyzed a sample of gliadin that had been digested with trypsin and pepsin. We observed that the developed assay could detect the peptides coming from the degradation of gliadin by these enzymes. We also analyzed a sample of hydrolyzed baby cereals in which the gliadin had been partially hydrolyzed during processing. These cereals contain a mixture of wheat, barley, rye, oat, and rice flours. The ethanolic extract obtained from the foodstuff was analyzed using the competitive ELISA. The partially hydrolyzed prolamines present in the sample were able to compete, and the quantitative assay could be performed.

We developed a similar assay using the $\mathrm{A} 1 \mathrm{moAb}$. The repeatability and reproducibility of the method were calculated from various standard curves performed on the same ELISA plate (intra-assay), and on different ELISA plates (inter-assay). The intra-assay coefficient of variation of the standards situated between $100 \mathrm{ng} / \mathrm{mL}$ of gliadin and $1.56 \mathrm{ng} / \mathrm{mL}$ of gliadin was found to be between $1.37 \%$ and $5.21 \%$, while the inter-assay coefficient of variation was between $3.16 \%$ and $11.78 \%$ for the same standards.

\subsubsection{Analysis of the epitope recognition of $\mathrm{G} 12$ and A1 moAbs}

To determine the epitope recognized by the G12 and A1 moAbs within the 33-mer peptide, fusions of the C-LYTAG coding sequence of the pALEXb plasmid (Biomedal S.L., Seville, Spain) were constructed with coding sequences of hepta- and octapeptides comprising the complete sequence of the 33-mer peptide (Figure 3A). The resulting plasmids were introduced by transformation into the REG1 strain of Escherichia coli, allowing for overexpression of the encoded fusion proteins upon induction (Biomedal S.L., Seville, Spain). The overexpressed bacterial extracts were analyzed by indirect ELISA using the anti33-mer A1 and G12 moAbs. Similarly, the anti-C-LYTAG 6B5L1 moAb (Biomedal, S.L., Seville, Spain) was used to establish that the designed protein was expressed intact in all cases. A reference signal in the bacterial extract containing the C-LYTAG-33-mer fusion protein was observed for all the moAbs assayed (A1, G12, and 6B5L1) (Figure 3B). Saturating signals were obtained in the indirect ELISA analysis using the anti-C-LYTAG $6 \mathrm{~B} 5 \mathrm{~L} 1 \mathrm{moAb}$ for all the analyzed fusion proteins, indicating that all fusion proteins were overexpressed (Figure 3B).

With regard to the determination of the sequence of recognition of the anti-33-mer moAbs (G12 and A1), a positive signal was detected only in the bacterial extracts containing the fusion peptides Pro63-Tyr69 (PQPQLPY) and Gln64-Pro70 (QPQLPYP) for the G12 moAb and in the bacterial extracts containing the fusion peptide Gln66-Pro72 (QLPYPQP) for the $\mathrm{A} 1 \mathrm{moAb}$ (Figure $3 \mathrm{~B}$ ). These results thus indicate that the region of recognition within the 
33-mer peptide for the G12 moAb is QPQLPY (common to the fusion proteins Pro63-Tyr69 and Gln64-Pro70) and that for the A1 moAb is QLPYPQP.
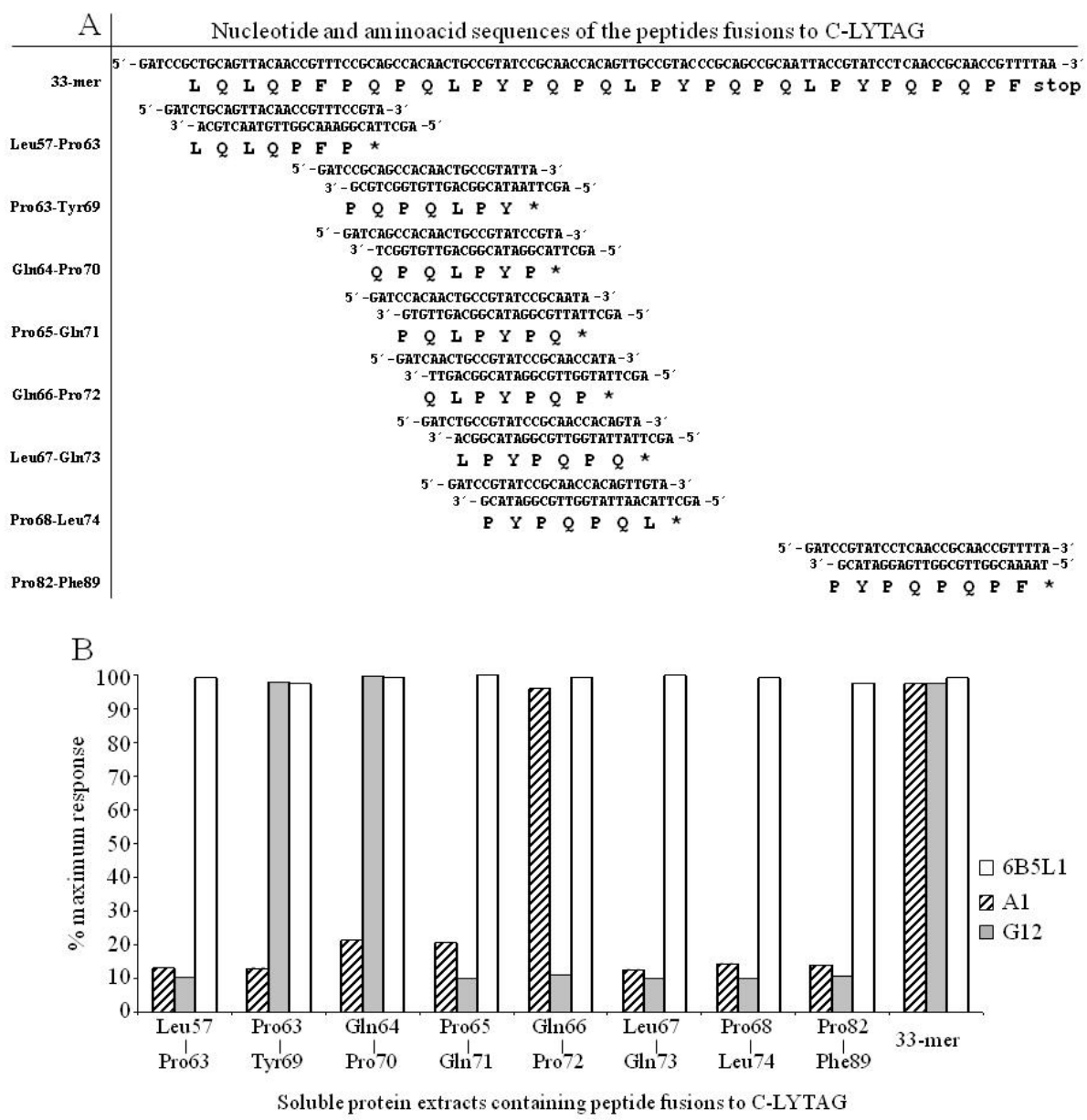

Fig. 3. Analysis of anti-33-mer moAb recognition regions in recombinant 33-mer peptide fragments expressed in E. coli. A. Nucleotide sequences and the deduced amino acid sequences of the encoded peptide fusions to C-LYTAG. B. Detection of C-LYTAG-peptide fusions by an indirect ELISA with the use of G12, A1, and 6B5L1 moAbs.

\subsubsection{Study of the relative affinity of the G12 moAb for different peptide variants derived from the regions of recognition}

The recognition sequence of the G12 moAb (QPQLPY) is repeated three times within the gliadin 33-mer peptide. To determine the relative affinity of G12 for this epitope, and for similar sequences present elsewhere in toxic prolamines, we constructed hexapeptide variants of the G12 epitope, two of which were designed based on their presence in the 
prolamines of barley and rye (Figure $4 \mathrm{~A}$ and $4 \mathrm{C}$ ). The affinity of the G12 moAb for different hexapeptide variants was determined in a competitive assay in which immobilized gliadin was challenged with QPQLPY-derivative peptides as soluble competitors (Figure 4A). The G12 moAb had high affinity for the peptide QPQLPF, reduced only four-fold relative to the previously identified epitope recognized by this moAb in the 33-mer, QPQLPY (Figure 4B). While the conservative replacement of tyrosine (QPQLPY) with phenylalanine (QPQLPF) did not drastically reduce the affinity of the G12 moAb, substitution with leucine (QPQLPL) reduced the affinity a thousand-fold, indicating the importance of this last position in determining affinity. A dramatic reduction in affinity was also observed for the peptide QPQQPY, with the affinity of the anti-33-mer G12 moAb decreasing as follows: QPQLPY>QPQLPF>>QPQLPL>QPQQPY.

A

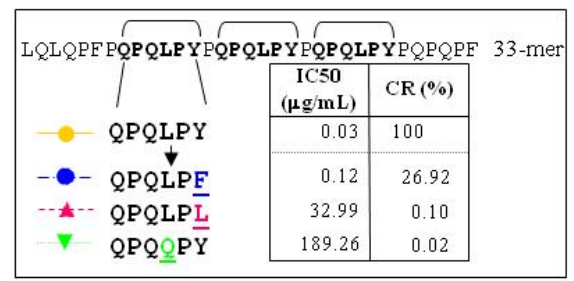

C

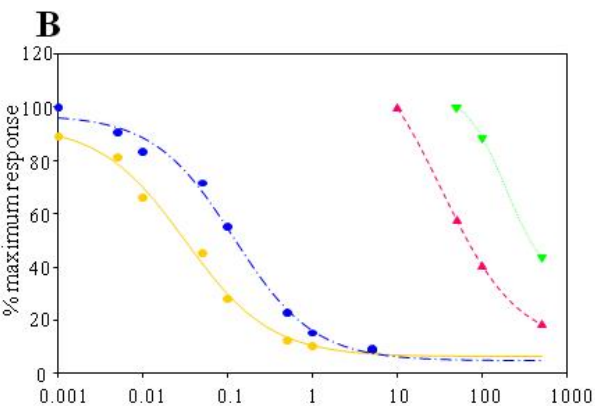

$\mu g / \mathrm{mL}$ (peptide)

\begin{tabular}{|c|c|c|}
\hline lin & $\gamma$-secali & $\mathrm{C}-\mathrm{h}$ \\
\hline & MKTLL ML A IL AMA TT I AT ANMOVNPSGQVQCPQQQPF PC & AMAMS IVTTARQLNPSHQELQS \\
\hline MVRVPVPQLQPQNPSQQQPQEQVPLVQQQQF & PQQSSPQQPQQPF PQQSQQPF PQQPQQSSPQPQQPYPQC & PQQPFLKQQSYLQQPYPQQPYLPQQPF PTPQQ \\
\hline PGQQQPF P PQQP YPQPQPF PSQQP YLQLQPF & PFPQQPQQPYPQQPQQPF PQQPQQPYPQQPQQPFPQQPC & FF PYLPQQTF PPSQQPNPLQPQQPF PLQPQPP \\
\hline P QP OLPY P OP OL PY P OP OL PY PQPQPF RPQC & QPVPQQPQQQF PQQPQQPVPQQPLQQF PQQPQQPF PQQP & QQPF PQPQQPNPQQPQQPF PRQPQQIVPQQPQ \\
\hline PYPQSQPQYSQPQQP ISQQQQQQQQQQQQKC & QQLVPQQSQQPF PQTQQPQQPF PQPQQPQQLFPQTQQSS & QPF PQQPQQPF PQPQQPFSWQPQQPF LQPLQL \\
\hline QQQQQQQILQQI LQQQL I PCRDVVLQQHS I ị & PQQPQQVTSQPQQPF PQAQP PQQSSPQSQQP YPQE PQQL & XPLQAQQPF PLQPQLPF PQPQQP IGQQP KQPL \\
\hline YGSSQVLQQSTYQLVQQLCCQQL WQIPEQSF & FPQSQQPQQPF PQPQQPQQPF PQPQPQTQQS IPQPQQPF & LQQPQQT IPQQPQQPF PLQPQQPF PQQPQQPL \\
\hline CQA I HNVNH H I I L HQQQQQQQQQQQQP LSQV & PQPQQPF PQSQEQF PQVHQPQQPSPQQQQPS IQLSLQQC & PQQPQQI ISQQPQQPF PLQPQQPF PQPQPF PQ \\
\hline SFQQPQQQYPSGQGSFQPSQQNPQRQGSVQF & LNPCKNVLLQQCSPVALVSSLRSKIFPQSECQVMQQQCC & EQPQQAFPLQPQQPF PEESEQI ITQQPF PLQP \\
\hline QQL PQFEE IRNL ALETLP AMCNVY IP PYCTI & QQL AQI PQQLQC Ä I HSVHH I I MQQEQRE GVQILLPQS & QQLF PQQPQQP PQPQQPF RQL P KY I IPQQPQ \\
\hline APVGIFGTNYR & $\begin{array}{l}\text { HQQHVGQG AL AQVQG I IQPQQLSQLEVVRSLVLQNLPTM } \\
\text { CNVYVPRQCSTIQAPF ASIVT IVIVH }\end{array}$ & QPFLLQPHQPQQPYAQQD IWSD IALLG \\
\hline
\end{tabular}

Fig. 4. Relative affinity of the G12 moAb for different peptide variants derived from its recognition region (QPQLPY). A. Amino acid sequences of the peptides. The G12 recognition sequence in the 33-mer peptide is in bold face. IC50 and CR values of the G12 moAb to peptides are indicated. B. Competition assay measuring the affinity of the G12 moAb for the peptides. Two separate assays were performed with the antibody, each with three repetitions. C. Localization of the peptides in the $\alpha$-gliadin (accession number: JQ1047), c-secalin (accession number: ABO32294.1), and C-hordein (accession number: AAA92333.1) sequences. The same colour code for labelling the peptides has been used in A, $\mathrm{B}$, and $\mathrm{C}$.

\subsubsection{Determination of the peptide sequence preferences for A1 moAb binding}

We also studied the relative affinity of the $\mathrm{A} 1 \mathrm{moAb}$ for its recognition sequence (QLPYPQP) and for related peptide variants by a competitive assay (Figure 5A). The 
peptides assayed for A1 were more numerous than those for G12 due to the longer heptapeptide recognition sequence contained in the 33-mer and to the suspected broader specificity of A1 for other prolamine sequences based on indirect ELISA assays (Figure 2). Figure 5 shows the affinity of the A1 moAb for the different peptides assayed; the IC50 was used to compare the affinity of A1 for each peptide.

$\mathbf{B}$

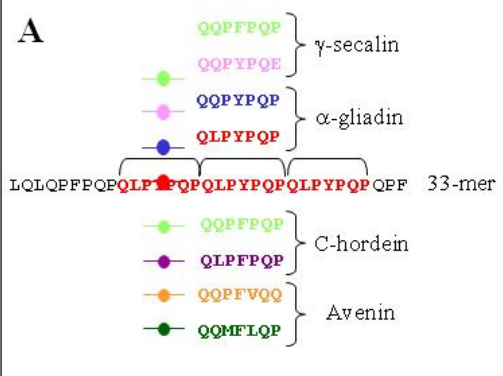

$\mathrm{C}$

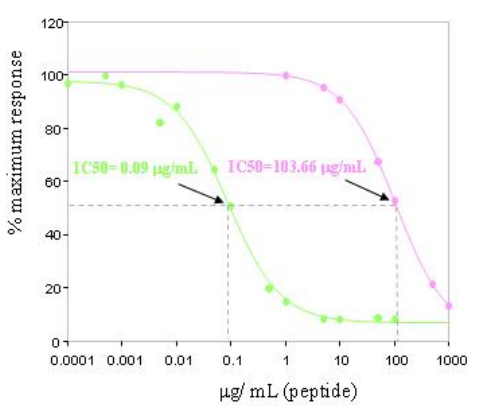

D

MKTFL TFVLLAMAMS IVTTARQLNPSHQELQS PQQPFLKQQSYLQQPYPQQPYLPQOPFPTPQQ C-hordein 1 FF PYLPQQTF P S QQPNPLQPQQPF PLQPQPP QPFPQQP OPIP QD QQPFSWQPQQPFLQPLQL XPLQAQQPFPLQPQLPFPQPQQP IGQQPKQPL LQQPOQT IPQOPOOPF PLOPQOPFPQQPQQPL

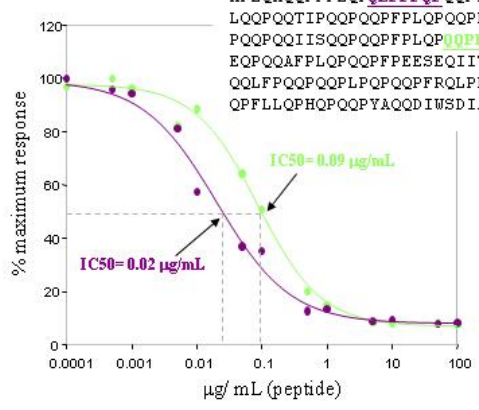

MVRVPPOLOPONPSOQQPQEOVPLVQQQQF $P$ GQQQPF PPQQPYPQPQPF PSQQP YLQLQPF PQ PQLPYPQPQLPYPQP QLPYPQP QPFRPQQPYP QSQPQYSQPQQP ISQQQQQQQQQQQQKQQQQQ QQQILQQILQQQL IPCRDVVLQQHS I Y YGSSQ VQR

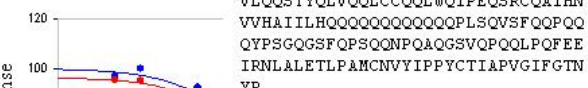
YR

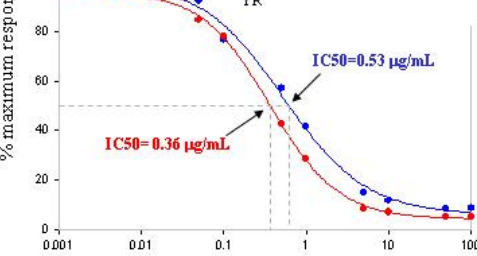

$\mu g / \mathrm{mL}$ (peptide)

$y$-secalin

MKTLL MLA ILAMATT IATANMQVNPSGQVQC PQ OPFP OP QQSSPQQPQQPFPQQSQQPFPQ QPQQSSPQPQQPYPQQPF PQQPQQPYPQQPQ QPF PQQPQQP YPQQPQQPF PQQPQQPVPQQP QQQF PQQPQQPVPQQP LQQF PQQPQQPF PQQ PQQLVPQQSQQPF PQTQQP OPFP QP QQPQQ LFPQTQQSSPQQPQQVTSQPQQPF PQAQPPQ QSSPQS QQPYP QE PQQLF PQSQQP QORER OP QQP OPFP OP QPQTQQSIPQP OPEP OP QQP F PQSQEQF PQVHQPQQPS PQQQQPS IQLSLQ QQLNPCKNVLLQQCSPVALVSSLRSKIF PQS ECQVMQQQCCQQL AQIPQQLQC A I I HSVVHA I IMQQEQRE GVQIL L PQSHQQHVGQG AL AOV QGI IQPQQLSQLEVVRSLVLQNLPTMCNVYV PROCSTIQAPF AS IVTG IVGH

\section{E}

\section{Avenin}

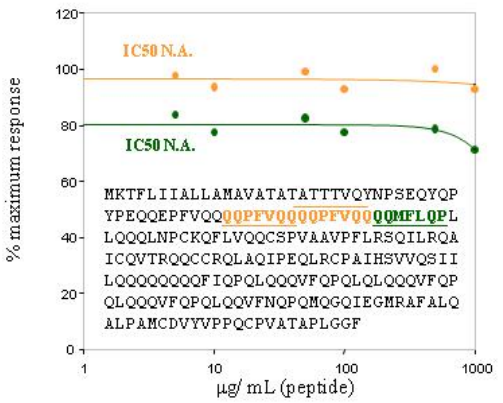

Fig. 5. Relative affinity of the $\mathrm{A} 1 \mathrm{moAb}$ for different peptide variants derived from its recognition region (QLPYPQP). A. Amino acid sequences of the peptides. The A1 
recognition sequence in the 33-mer peptide is in red. B, C, D, and E. Competition assay for detection of the affinity of the A1 moAb for the peptides and their localization in $\alpha$-gliadin (B; accession number: JQ1047), c-secalin (C; accession number: ABO32294.1), C-hordein (D; accession number: AAA92333.1), and avenin (E; accession number: AAA32716.1). Two separate assays were performed with the moAb, each with three repetitions. IC50 values of the A1 moAb to peptides are indicated. N.A.: Not applicable. The colour code for labelling the peptides is the same as that used in A.

Notably, two peptides present in secalin and hordein (QQPFPQP and QLPFPQP, Figures 5C and 5D, respectively) showed higher affinity for the A1 moAb than did the 33-mer-derived recognition sequence peptide (QLPYPQP). This suggests that the fourth residue in the recognition sequence is substantially important to A1 recognition, whereas the second position is not. Consistent with this, gliadin peptides QLPYPQP and QQPYPQP showed comparable affinity for the moAb (Figure 5B). The affinity of the anti-33-mer A1 moAb for epitopes present in coeliac-toxic cereals decreased as follows: QLPFPQP>QQPFPQP>QLPYPQP>QQPYPQP $>>Q Q P Y P Q E$.

The affinity for the sequence included in the wheat gliadin 33-mer was not as high as for QQPFPQP, which is one of the most abundant sequences in secalin and hordein, similarly to the 33-mer epitope in gliadin. This may explain why, despite its lower affinity for the 33-mer peptide relative to the $\mathrm{G} 12 \mathrm{moAb}$, the $\mathrm{A} 1 \mathrm{moAb}$ had a higher sensitivity for the whole range of toxic cereals tested in this study. The A1 moAb may therefore be useful as a sensitive detection tool for identifying coeliac-toxic peptides in complex foodstuffs.

Preliminary attempts to find an avenin epitope gave no positive results (Figure 5E). The prolamines in oats represent much less of the total seed proteins than those in the other cereals. Furthermore, the amount of proline residues contained in avenins $(10 \%)$ is about two-thirds that in the prolamines of wheat (gliadins and glutenins), barley (hordeins), and rye (secalins). In any case, we tested certain previously proposed potential avenin epitopes located in the avenin regions with the highest content of proline residues, regions also rich in glutamine, but could not obtain any reactivity to the $\mathrm{A} 1 \mathrm{moAb}$.

To study the relative importance of glutamine and proline residues in epitope selection by the $\mathrm{A} 1 \mathrm{moAb}$, single substitutions or deletions were made to these amino acids in the recognition sequence (QLPYPQP). We performed the analysis with the A1 moAb rather than with the G12 moAb because A1 has higher sensitivity for prolamines from toxic cereals. When the first glutamine of the A1 recognition sequence was eliminated (LPYPQP), the affinity for A1 decreased significantly, consistent with the results from epitope scanning with the C-LYTAG fusions (Figure 3). Substitutions of each proline residue in the recognition sequence with a serine residue decreased A1 affinity markedly. This effect was greatest when the substitution was made in the second proline position (QLPYSQP), resulting in a CR that was practically zero.

These results indicate that the initial glutamine residue and all three prolines of the epitope QLPYPQP were important for their recognition by A1, suggesting that this moAb could serve as a tool for monitoring enzymatic degradation of toxic peptides by potentially therapeutic glutamine- and proline-specific proteases. 


\subsubsection{Use of the $A 1$ moAb to monitor gluten detoxification by candidate glutenases}

Oral administration of glutamine- and proline-specific proteases (i.e., glutenases) is a potential therapeutic alternative (or adjunct) to a gluten-free diet (Stepniak \& Koning, 2006; Cerf-Bensussan et al., 2007). However, validation of the efficacy of these enzymes at detoxifying gluten in vitro must precede clinical testing, and such validation currently relies on low-throughput, technically challenging cell-culture-based assays (Siegel et al., 2006; Gass et al., 2007; Stepniak \& Koning, 2006) or on polyclonal anti-gliadin-antibody-based ELISA assays that are only grossly quantitative (Gass et al., 2007). A competitive ELISA using an anti-33-mer moAb would enable high-throughput, highly quantitative testing of gluten detoxification by candidate therapeutic glutenases.

We digested commercial whole-wheat bread under mock gastric conditions for 60 min with pepsin supplemented either with EP-B2 at varied concentrations (Figure 6A), or with a fixed EP-B2 concentration plus varied concentrations of SC PEP (Figure 6B). Dilution series of the quenched digests were prepared in parallel with a calibration dilution series of chemically synthesized 33-mer peptide, and these were tested against fixed 33-mer in an indirect competitive ELISA using A1 moAb. Treatment of whole-wheat bread with EP-B2 reduced the concentration of the 33-mer and close analogues by up to 10-fold in a dose-dependent manner (Figure 6A). This is consistent with the observation that EP-B2 cleaves the 33-mer after Gln66, Gln73, and Gln80 (Bethune et al., 2006), cleavages expected to extirpate the affinity of A1 for the resultant fragments.

The combination of EP-B2 + SC PEP further reduced antigen concentrations by at least an additional 10-fold to levels undetectable by our methods (Figure 6B). This is again consistent with previously published results, in which EP-B2 substantially detoxified similar bread digests, but the synergistic combination of EP-B2 with SC PEP was required to dramatically reduce the intestinal T-cell reactivity of these digests (Gass et al., 2007). The intensity of the signal obtained with the A1 moAb in our assay was therefore proportional to the potential damage caused to a CD patient by a commercial gluten source (Morón et al., 2008b).

\subsubsection{Analysis of the recognition of anti-33-mer moAbs for deamidated and innate gluten peptides}

CD is closely associated with genes that code for human leukocyte antigens DQ2 and DQ8. These have been shown to bind with high affinity to gliadin-derived peptides in which specific glutamine residues in key positions have been converted to glutamic acid by transglutaminase-2-mediated deamidation (Alaedini \& Green, 2005; Sollid \& Khosla, 2005). A moAb capable of discriminating between native and deamidated gluten peptides would be a valuable research tool for monitoring the fate of digested prolamine peptides. To test the relative sensitivity of each moAb for the deamidated 33-mer peptide, a peptide (QPQLPYPQP) was designed that represented a region of recognition common to the two moAbs, together with the same peptide deamidated (QPELPYPQP).

The affinities of the A1 and G12 moAbs for these peptides were determined by a competitive assay in which immobilized gliadin was challenged with peptides as competitors. The affinity of the G12 moAb for the deamidated peptide was about forty times higher than that of the A1 moAb. However, both moAbs recognized the non-deamidated peptide with $>100$-fold greater affinity than they did the deamidated peptide. In 
A

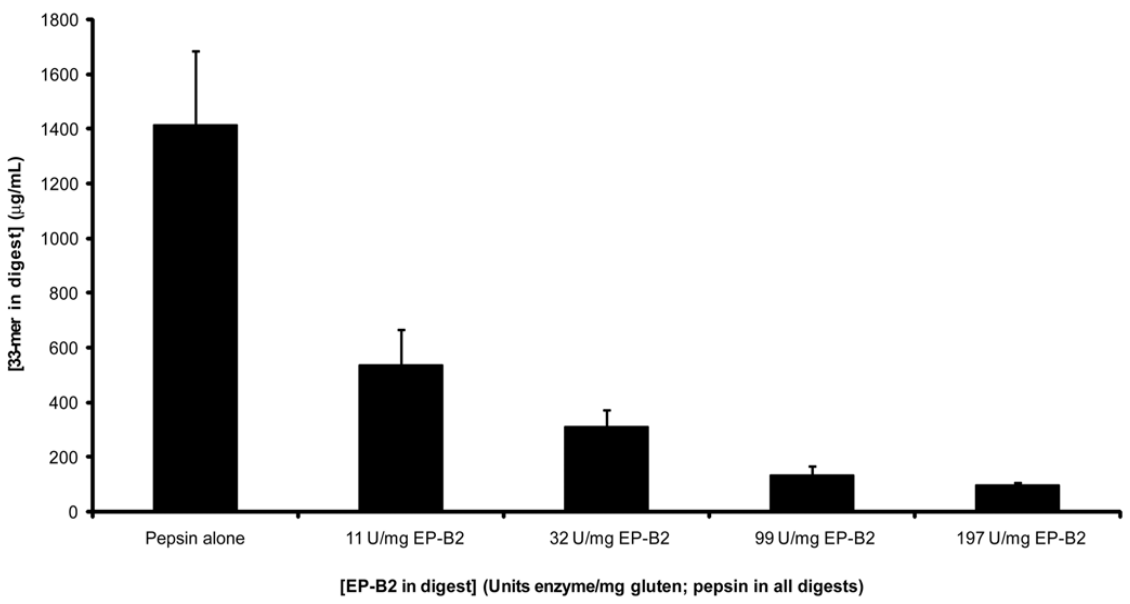

B

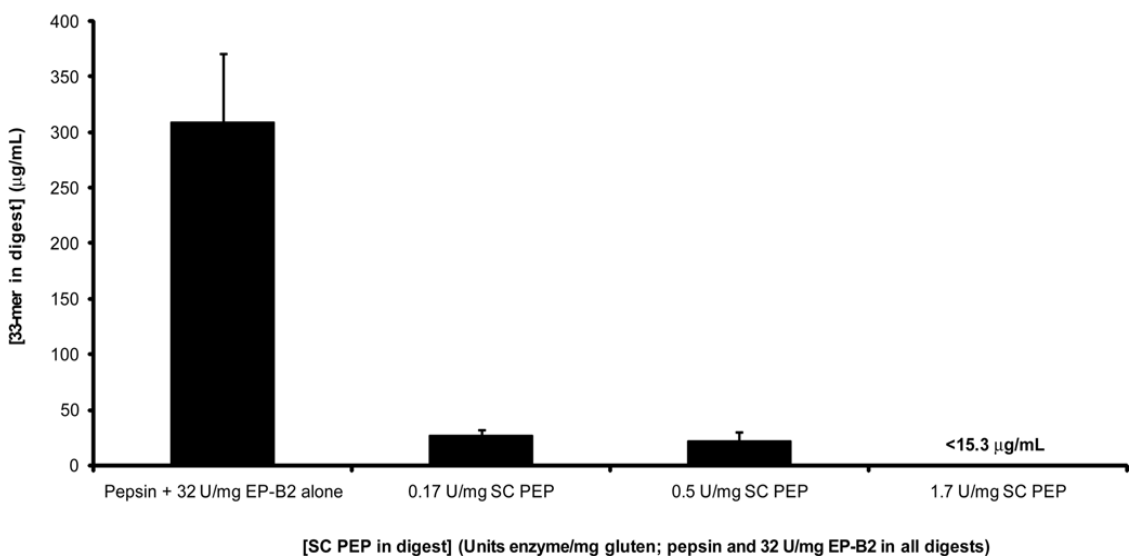

Fig. 6. Indirect competitive ELISA using A1 moAb to test whole-wheat bread digests for 33mer content. A. Concentration of 33-mer $(\mathrm{mg} / \mathrm{mL})$ in whole-wheat bread digests containing $0.6 \mathrm{mg} / \mathrm{mL}$ pepsin supplemented with specified concentrations of recombinant proEP-B2 $(\mathrm{U} / \mathrm{mg}$ gluten). B. Concentration of 33-mer $(\mathrm{mg} / \mathrm{mL})$ in whole-wheat bread digests containing $0.6 \mathrm{mg} / \mathrm{mL}$ pepsin and $32 \mathrm{U} / \mathrm{mg}$ EP-B2 supplemented with specified concentrations of recombinant SC PEP (U/mg gluten). The concentration of 33-mer in each digest was determined by comparison with a synthetic 33-mer standard curve. Two separate assays were performed with the antibody, each with three repetitions.

combination with a previously characterized, commercially available moAb that has 20 -fold greater affinity for the deamidated form of an overlapping gluten peptide than for its nondeamidated counterpart, G12 and A1 moAbs may be useful for future studies on transglutaminase-2-mediated gluten peptide deamidation. 
The innate immune response to gluten plays a key role in the development of CD (Fehniger \& Caligiuri, 2001; Bernardo et al., 2007). This response is mediated by interleukin 15 (a typical cytokine of the innate immune system) and elicited by the toxic peptide p31-49 (19mer), derived from alpha-gliadin. To test whether the anti-33-mer A1 and G12 moAbs recognized peptide p31-49, competitive ELISAs with each moAb were performed. The A1 moAb was able to detect p31-49 (IC50 $3.18 \mathrm{mg} / \mathrm{mL}$ ). The G12 moAb showed no affinity for the 19-mer peptide.

These results were consistent with our previous identification of the QQPYPQP peptide, included in p31-49, as a permissive epitope for the A1 moAb. Therefore, this moAb shows an interesting range of peptide recognition that includes gliadin peptides involved in both the adaptive and the innate immunological responses in CD.

\section{The oats controversy: selection of oat varieties with no toxicity in coeliac disease}

There is an ongoing debate concerning the presence or absence of gluten in oats. Traditionally, treatment with a GFD has excluded not only wheat, barley, and rye, but also oats. Oats differ from other cereals in their prolamine content. The percentage of proline and glutamine (amino acids abundant in toxic regions) in avenin is lower than in other toxic cereals (Figure 8).

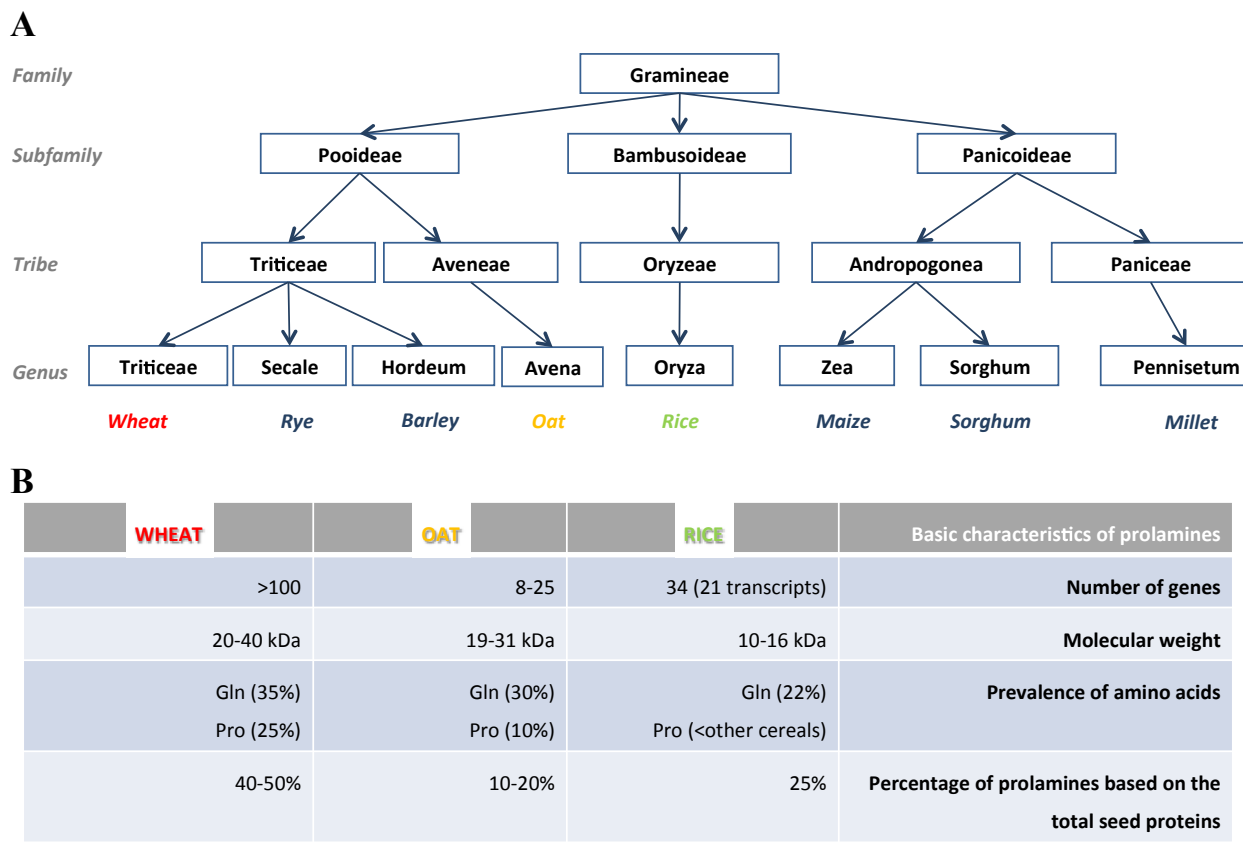

Fig. 8. Taxonomy and basic characteristics of the prolamines of oats in relation with other cereals. A. Taxonomy of oats in relation with other cereals. B. Basic characteristics of the prolamines of wheat, oats, and rice. 
However, there is still some debate about the safety of oats (Pulido et al., 2009). Several in vivo and in vitro studies have indicated that the majority of coeliac subjects can tolerate moderate amounts of pure oats. Some countries permit the use of oats in "gluten-free" products, e.g. Gluten-Free Oats ${ }^{\circledR}$. According to the Codex Standard for food for special dietary use for persons intolerant to gluten, CODEX STAN118-1979 (revised 2008, http://www.codexalimentarius.net/web/more_info.jsp?id_sta=291), oats can be tolerated by most, but not all, people who are gluten-intolerant. Therefore, the permitting of oats that are not contaminated with wheat, rye, or barley in foods covered by this standard may be determined at the national level. Moreover, according to the Commission Regulation (EC) No 41/2009 (http://eur-lex.europa.eu/LexUriServ/LexUriServ.do?uri=OJ:L:2009:016:0003: 0005:EN:PDF) concerning the composition and labelling of foodstuffs suitable for people intolerant to gluten, a major concern is the contamination of oats with wheat, rye, or barley that can occur during grain harvesting, transport, storage, and processing. Therefore, the risk of gluten contamination in products containing oats should be taken into consideration with regard to labelling of those products. Certain cross-reactivity with gliadin-specific antibody has been attributed to wheat contamination in oat-based food (Pulido et al., 2009).

However, other authors shown clear evidence that avenins have the ability to induce the activation of mucosal T-cells, causing gut inflammation and villous atrophy (Pulido et al., 2009). Arentz-Hansen et al. (2004) described the intestinal deterioration suffered by some CD patients following the consumption of oats while on GFD. Avenin can trigger an immunological response in these patients similar to the response produced by the gluten of wheat, rye, or barley. The monitoring of 19 adult coeliac patients who consumed $50 \mathrm{~g} /$ day of oats over twelve weeks showed that one of the subjects was sensitive to oats. Therefore, it is crucial to clarify either qualitatively or quantitatively the potential immunotoxicity of oats to coeliac patients (Arentz-Hansen et al., 2004; Pulido et al., 2009).

In a previous work, we obtained two moAbs, G12 and A1, against the 33-mer peptide (Morón et al., 2008a). Our results suggested that the reactivity of these moAbs was correlated with the potential immunotoxicity of those dietary grains from which the proteins were extracted (Morón et al., 2008b; Ehren et al., 2009). These antibodies are able to recognize with great sensitivity peptides (besides the 33-mer peptide) immunotoxic for coeliac patients. The sensitivity and epitope preferences of these antibodies were found to be useful for detecting gluten-relevant peptides to infer the potential toxicity of food for coeliac patients. The G12 moAb showed cross-reactivity that served to detect a certain amount of oat avenins, although with lower sensitivity than the hordein, gliadin, and secalin (Morón et al., 2008a) The oats controversy appears to be a unique case for exploring this issue, because cases of intermediate immunotoxicity could be expected and the correlation of potential toxicity and analytical signal could be assessed.

\subsection{Relative affinity of the G12 moAb for different varieties of oats}

Different oat varieties monitored for their purity and by their distinct protein pattern (Figure 9), were used to examine differences in G12 moAb recognition by ELISA and Western blot. 

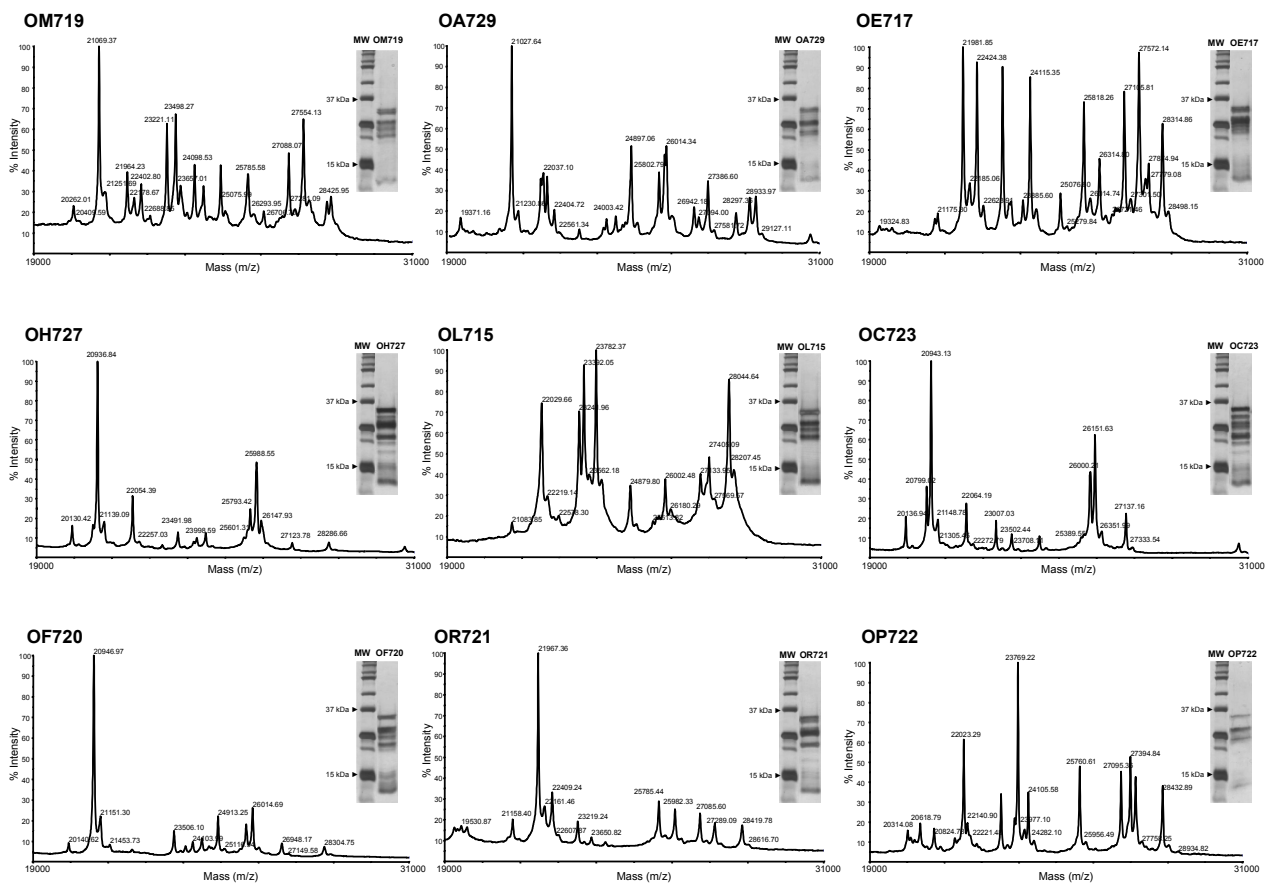

Fig. 9. Comparison of avenin fractions extracted from oat varieties studied. Avenin spectra were determined by matrix-assisted laser desorption/ionization time-of-flight mass spectrometry of the 9 oat varieties. Analysis of proteins extracted from the oat varieties by SDS-PAGE. MW: Protein molecular weight marker.

To determine whether the G12 moAb had distinct reactivity to the different oat varieties, the affinity of the G12 moAb was determined by competitive ELISA. The G12 moAb showed different affinity for the oat varieties tested (Figure 10A). Therefore, three groups of oat varieties could be clearly distinguished depending on their recognition by the G12 moAb: a group of high affinity towards the antibody (OM719, OA729 and OE717), a group of intermediate recognition (OH727, OL715, and OC723), and another group comprising oats that were not recognized by the G12 moAb (OF720, OR721, and OP722). The alternative anti-33-mer A1 moAb provided equivalent results (data not shown).

In order to quantify the affinity of the oat varieties for the G12 moAb, the IC50 and the CR were determined for each variety (Figure 10B). The IC50 is defined as the concentration that produces a reduction of $50 \%$ in the peak signal in the ELISA. The CR was determined as (IC50 of the oat variety that presents the greatest affinity for the antibody/IC50 of each variety assayed) $\times 100$. Varieties OE717 and OA729 respectively showed a CR of around $60 \%$ and $75 \%$ with respect to the most sensitive variety (OM719). Varieties OH727, OL715, and OC723, with a CR of $25 \%, 24 \%$, and $12 \%$, respectively, were recognized by the G12 moAb, but with a lower sensitivity. The avenins of OF720, OR721, and OP722 were not recognized by the G12 moAb, as in the case of the negative control (rice). 
In order to confirm the ELISA results with another immunological technique and to identify protein patterns with cross-reactivity to the anti-33-mer antibody, immunoblotting electrophoresis analyses were performed. The results (Figure 10C) showed that the G12 moAb had affinity for the varieties OM719, OA729, OE717, OH727, OL715, and OC723. However, the antibody did not react with varieties OF720, OP722, and OR721. The variability in reactivity demonstrated by Western blot thus correlated with the previously presented ELISA results. These results suggested the presence of different prolamine subunits in the oat varieties, differing in both their amino acid composition and length.

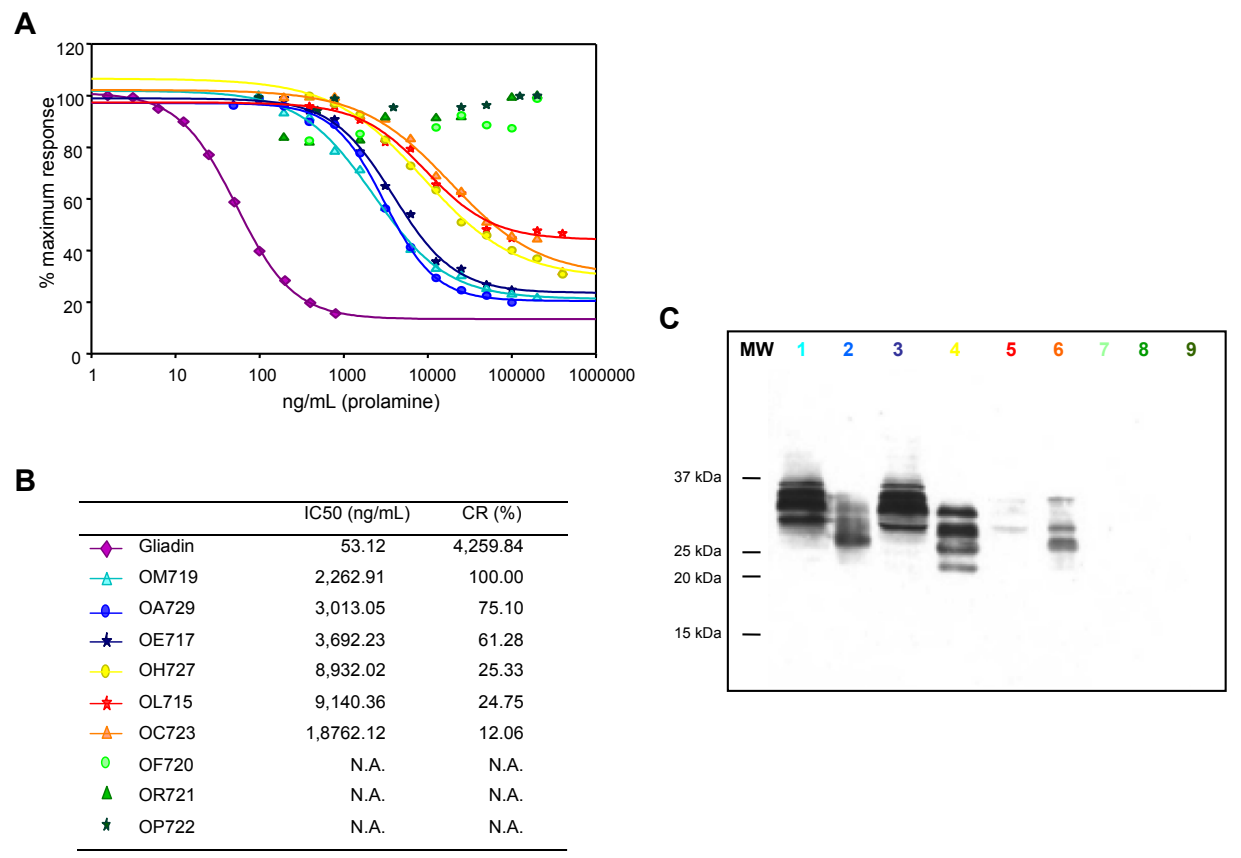

Fig. 10. Relative affinity of the G12 anti-33-mer moAb for different oat varieties and gliadin. A. Competitive ELISA using the G12-HRP anti-33-mer antibody to determine the relative affinity of this antibody against the different varieties of oats. Three assays were performed, with three replicates of each. Gliadin was used as positive control. B. IC50 and CR of the different oat varieties. N.A.: Not applicable. C. Western blot analysis of toxic fractions from different prolamines extracted from the grains of oats. Membranes were stained with G12 antibody. The colour code for labelling the varieties is the same as that used in A and B.

\subsection{Determining the concentration of immunoreactive peptides in oats}

To evaluate the relative amount of immunotoxic epitopes present in the prolamines of different oat varieties, one variety was chosen from each of the three groups previously identified for their affinity towards the G12 moAb. Thus, OM719 represented the group with greatest affinity towards the G12 moAb, OH727 those of intermediate reactivity, and OF720 those not recognized by this antibody. 
The presence of immunoreactive peptides was determined by the G12 moAb competitive ELISA, using the 33-mer peptide as the standard curve. The presence of 33-mer and close analogues in the most reactive oat variety, OM719, was of the order of $1,340 \mathrm{ng} / \mathrm{mg}$ of avenin (Figure 11). In OH727, the levels of 33-mer were some 4-fold lower than in OM719. However, in the case of OF720, the concentration of 33-mer was reduced more than 1,300fold with respect to OM719, reaching levels undetectable by this method.

This result was consistent with earlier results obtained using IC50 and CR, and by Western blot, and at the same time indicated the enormous difference between some varieties and others regarding the presence of sequences that are immunoreactive for coeliac patients.

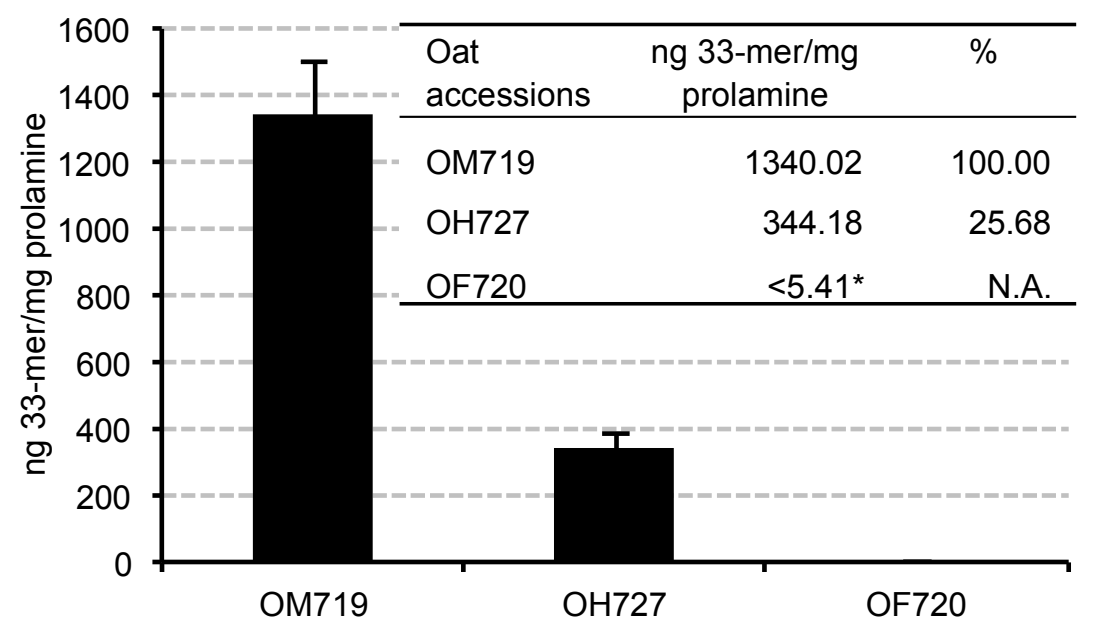

Fig. 11. Detection of concentration of 33-mer peptide in different oat varieties. The concentration of 33-mer was determined by competitive ELISA using the G12 monoclonal antibody. Different dilutions were tested independently for each oat variety, each with three repetitions.

\subsection{Correlation between $\mathrm{G} 12$ moAb reactivity and immunogenicity of different oat varieties}

To determine whether the variations in the reactivity of the anti-33-mer G12 in the different oat varieties were correlated with the greater or lesser immunogenicity of the cereal, we directly challenged the cereal extracts with appropriate cells obtained from coeliac patients. The clinical and immunological characteristics of coeliac patients are presented in Table 1.

Immunogenicity was determined by T-cell proliferation and IFN- $\gamma$ production. Three cultivars of oats were selected -one variety was chosen from each previously identified group (OM719, OH727 and OF720). We tested whether there was a correlation between their potential immunotoxicity for coeliac patients and their reactivity with the G12 moAb. 
The avenin of the oat varieties, gliadin, and oryzein were subjected to peptic, trypsic, and chymotrypsin sequential digestion and treated with tTG. Cell proliferation and IFN- $\gamma$ release in culture medium were measured as indices of lymphocyte activation.

\begin{tabular}{llllllll} 
Patient & Sex & Age (years) & $\begin{array}{l}\text { Atrophy grade } \\
\text { MARSH }\end{array}$ & AAEM & AATG HLA DQB1 & HLA DRB1 \\
& & & MAR & & \\
\hline Coeliac 1 & Male & 6 & III b & + & 252 & $0201-0202$ & $3-7$ \\
Coeliac 2 & Female 3 & III a & + & 20 & $0201-0202$ & $3-7$ \\
Coeliac 3 & Male & 13 & III b & - & 2 & $0202-0301$ & $7-11$ \\
Coeliac 4 & Female 5 & III b & + & 102 & $0201-0604$ & $3-11$ \\
Coeliac 5 & Female 9 & III b & + & 139 & $0201-0202$ & $3-7$ \\
Coeliac 6 & Female 2 & III b & + & 15 & $0302-0301$ & $4-4$ \\
Coeliac 7 & Female 4 & III b & + & 28 & $0201-0501$ & $1-3$ \\
Coeliac 8 & Female 7 & II & + & 111 & $0201-0202$ & $3-7$ \\
Coeliac 9 & Male & 10 & III b & + & 165 & $0202-0301$ & $7-11$ \\
Coeliac 10 & Male & 5 & III b & + & 118 & $0201-0202$ & $3-7$ \\
\hline
\end{tabular}

Table 1. Clinical data of coeliac patients. AAEM: anti-endomysial antibody. AATG: antitransglutaminase antibody expressed $\mathrm{U} / \mathrm{mL}$.

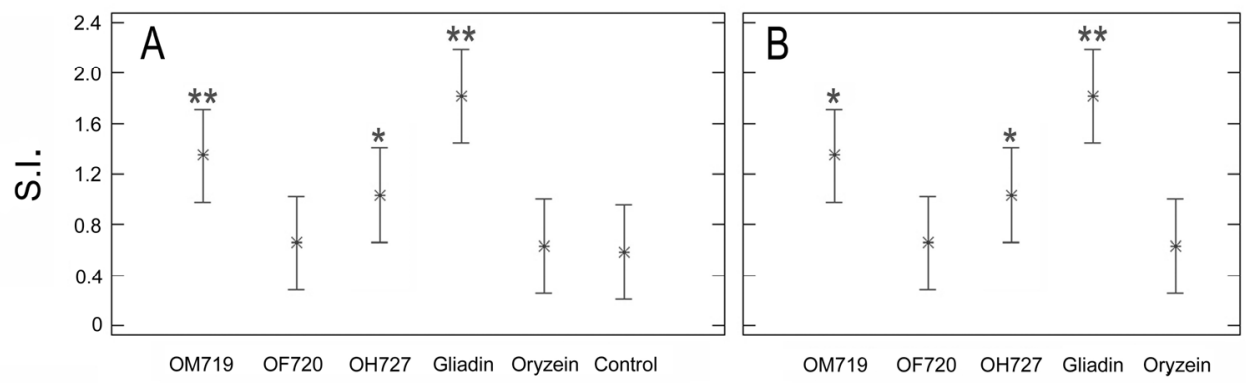

Fig. 12. Proliferative responses of T-cells to deamidated peptides of prolamine from three different oat varieties. PBMCs were exposed to tTG-treated prolamine-digest stimulation for $48 \mathrm{~h}$. Gliadin and oryzein were used as positive and negative control, respectively. The experiments were performed in duplicate, and the mean S.I. value \pm SDM is shown. A. The S.I. values of T-cells exposed to prolamine digests were statistically significant with respect to the control (healthy patient) and B. with respect to oryzein. ${ }^{*} \mathrm{p}<0.05,{ }^{* *} \mathrm{p}<0.005$.

We found a significant increase of T-cell proliferation in cultures incubated with OM719 and gliadin (S.I. $=1.3 \pm 0.7$ and $1.8 \pm 0.9$, respectively), and with OH727 (S.I.=1.02 \pm 0.5 ). This 
clearly showed that gliadin and OM719 displayed the highest activity, and were potentially the most immunogenic (Figure 12). The incubation with OF720 increased cell proliferation (S.I. $=0.65 \pm 0.4)$ similarly to that with oryzein (S.I. $=0.62 \pm 0.3$ ). We included the values presented in healthy patients (control) as reference values to compare the effect of peptides in coeliac patients, under the same conditions of cell culture. Release of IFN- $\gamma$ in the culture medium after the exposure of coeliac peripheral T-lymphocytes to deamidated avenin peptides was assessed (Figure 13). According to this assay, gliadin and prolamines from OM719 were very immunogenic, with the highest values of IFN- $\gamma$ release $(9.4 \pm 0.76 \mathrm{pg} / \mathrm{mL}$ and $7.9 \pm 0.57 \mathrm{pg} / \mathrm{mL}$, respectively), while the exposure to OH727 induced a lower mean value of IFN- $\gamma(4.8 \pm 0.95 \mathrm{pg} / \mathrm{mL})$. Finally, OF720 and oryzein were the least immunogenic $(3.4 \pm 1.09 \mathrm{pg} / \mathrm{mL}$ and $2.3 \pm 0.89 \mathrm{pg} / \mathrm{mL}$, respectively).

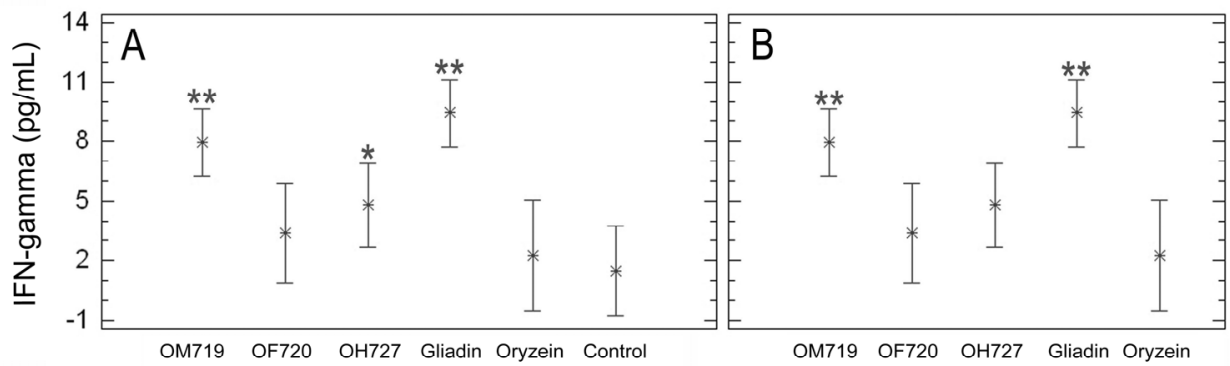

Fig. 13 IFN- $\gamma$ production by T-cells with prolamine digests from three different oat varieties. T-lymphocytes were stimulated with digested prolamines after treatment with tTG. IFN- $\gamma$ production was evaluated by ELISA after $48 \mathrm{~h}$ of incubation. Results are shown as means of duplicate wells and expressed as $\mathrm{pg} / \mathrm{mL}$. Gliadin and oryzein were used as positive and negative control, respectively. A. Significant with respect to healthy control and B. with respect to oryzein. ${ }^{*} \mathrm{p}<0.05,{ }^{* *} \mathrm{p}<0.005$.

\section{Conclusion}

Immunotoxic gluten peptides that are recalcitrant to degradation by digestive enzymes appear to trigger CD. A 33-mer peptide from $\alpha-2$ gliadin has been identified as a principal contributor to gluten immunotoxicity. A gluten-free diet is currently the only therapy for $\mathrm{CD}$ patients; therefore, the characterization and quantification of the toxic portion of gluten in foodstuffs is crucial to avoid coeliac damage. Our work was to develop tools for immunological assays to measure cereal fractions that are immunotoxic to CD patients. Two monoclonal antibodies, G12 and A1 (anti-33-mer antibodies), were developed against a highly immunotoxic gliadin 33-mer peptide. 
Compared with other ELISAs, those based on these antibodies showed a broader specificity for prolamines that are toxic to CD patients, along with a higher degree of sensitivity, accuracy, and reproducibility. Furthermore, these antibodies have shown no cross-reactivity with any known food ingredient including soybean, as observed in the Codex standard R5 ELISA.

Gliadin and other immunotoxic prolamines are sometimes hydrolyzed in food and drinks, which may result in the underestimation of the net amount of toxic fractions by other lessspecific antibodies that are not targeted at strictly immunotoxic peptides. The anti-33-mer antibodies have shown their practical efficacy as analytical tools in quantifying food toxicity for CD patients. These antibodies were assessed, and shown to be very suitable to provide a routine assay to determine gluten content, since their sensitivity and specificity were superior to previously described gluten immunoassays. Furthermore, the reactivity of these moAbs was correlated with the potential immunotoxicity of those dietary grains from which the proteins were extracted. T-cell reactivity analysis and enzymatic detoxification of the proteins showed that the signal of these antibodies was correlated with the sample's potential toxicity for coeliac patients.

We show, using the anti-33-mer antibodies raised against the toxic fragment, that oat immunogenicity for coeliac disease patients varies according to the variety of cultivar. We showed that the intensity of the signal obtained with the antibody was proportional to the potential damage caused to CD patients. We have proved that the reactivity of these antibodies with different varieties of oats was correlated with the immunotoxicity of those dietary grains from which the proteins were extracted, thereby providing a rational explanation of why some oats trigger immunological response, and a solution of how to avoid the presence of such varieties in gluten-free diets. The possibility of assessing the potential immunotoxicity to coeliac patients with a simple assay is an attractive idea with obvious applications in food analysis. Our study gives new insights about the dilemma of oats in coeliac disease, and suggests practical methods to select varieties of oats that are tolerable for coeliac patients, and at the same time, offers the possibility of measuring potential immunotoxicity by a simple immunological method, regardless of the cereal's origin. The experimental design to resolve those issues served to shed light on an ongoing controversy regarding the contradictory conclusions from clinical studies to establish the tolerance of coeliac patients to oats. Our work should also be taken into consideration by food safety regulations - in particular, the labelling of gluten-free products that may contain oats. Therefore, this work may potentially have a social impact besides its relevance in basic and clinical research of coeliac disease.

This work suggests considering whether the most practical way to measure food safety for coeliac patients is to quantify the amount of the immunoreactive prolamine epitopes, rather than the amount of any gluten in a given sample. The two antibodies have been used to develop different analytical techniques, including ELISA (competitive and sandwich) and immunochromatographic strips for routine assays (Glutentox®, Biomedal S.L., Seville, Spain). The A1- and G12-based immunoassays appear to be a promising approach to detect, with a direct relationship, any sample's net toxicity for coeliac patients. 


\section{Acknowledgment}

Carolina Sousa gratefully acknowledges funds from the Asociación de Celíacos de Madrid (ACM, Madrid, Spain), the Ministerio de Ciencia e Innovación, and the Instituto Andaluz de Biotecnología (IAB).

\section{References}

Alaedini, A. \& Green, P.H.R. (2005). Narrative review: celiac disease: understanding a complex autoimmune disorder. Annasl of Internal Medicine, Vol.142, No.4, (February 2005), pp.289-299, ISSN 0003-4819.

Arentz-Hansen, H., Fleckenstein, B., Molberg, Ø., Scott, H., Koning, F., Jung, G., Roepstorff, P., Lundin, K.E. \& Sollid, L.M. (2004). The molecular basis for oat intolerance in patients with celiac disease. PLoS Medicine, Vol.1, No.1, (October 2004), pp.84-92, ISSN 1549-1277.

Bernardo, D., Garrote, J.A., Fernández-Salazar, L., Riestra, S. \& Arranz, E. (2007). Is gliadin really safe for non-celiac individuals? Production of interleukin 15 in biopsy culture from non-celiac individuals challenged with gliadin peptides. Gut, Vol.56, No.6, (June 2007), pp.889-890, ISSN 1468-3288.

Bethune, M.T., Strop, P., Tang, Y., Sollid, L.M. \& Khosla, C. (2006). Heterologous expression, purification, refolding, and structural-functional, characterization of EP-B2, a selfactivating barley cysteine endoprotease. Chemistry \& Biology, Vol.13, No.6, (June 2006), pp.637-647, ISSN 1074-5521.

Bethune, M.T. \& Khosla, C. (2008). Parallels between pathogens and gluten peptides in celiac sprue. PLoS Pathogens, Vol.4, No.2, (February 2008), pp.e34, ISSN 15537366.

Cerf-Bensussan, N., Matysiak-Budnik, T., Cellier, C. \& Heyman, M. (2007). Oral proteases: a new approach to managing coeliac disease. Gut, Vol.56, No.2, (February 2007), pp.157-160, ISSN 1468-3288.

Collin, P., Thorell, L., Kaukien, K. \& Mäki, M. (2004). Alimentary Pharmacology \& Therapeutics, Vol.19, No.12, (June 2004), pp.1277-1283, ISSN 1365-2036.

Comino, I., Real, A., de Lorenzo, L., Cornell, H., López-Casado, M.A., Barro, F., Lorite, P., Torres, M.I., Cebolla, A. \& Sousa, C. (2011). Diversity in oat potential immunogenicity: basis for the selection of oat varieties with no toxicity in coeliac disease. Gut, Vol.60, No.7, (February 2011), pp.915-922, ISSN 1468-3288.

Ehren, J., Morón, B., Martin, E., Bethune, M.T., Gray, G.M. \& Khosla, C. (2009). A food-grade enzyme preparation with modest gluten detoxification properties. PLoS One, Vol.4, No.7, (July 2009), pp.e6313, ISSN 1932-6203.

Ellis, H.J., Rosen-Bronson, S., O'Reilly, N. \& Ciclitira, P.J. (1998). Measurement of gluten using a monoclonal antibody to a coeliac toxic peptide of A-gliadin. Gut, Vol.43, No.2, (August 1998), pp.190-195, ISSN 1468-3288.

Fehniger, T.A. \& Caligiuri, M.A. (2001) Interleukin 15: biology and relevance to human disease. Blood, Vol.97, No.1, (January 2001), pp.14-32, ISSN 1528-0020. 
Gass, J., Bethune, M.T., Siegel, M., Spencer, A. \& Khosla, C. (2007). Combination enzyme therapy for gastric digestion of dietary gluten in celiac sprue patients. Gastroenterology, Vol.133, No.2, (August 2007), pp.472-480, ISSN 0016-5085.

Khosla, C., Gray, G.M. \& Sollid, L.M. (2005). Putative efficacy and dosage of prolyl endopeptidase for digesting and detoxifying gliadin peptides. Gastroenterology, Vol.129, No.4, (October 2005), pp.1362-1363, ISSN 0016-5085.

Mitea, C., Havenaar, R., Drijfhout, J.W., Edens, L., Dekking, L. \& Koning, F. (2008). Efficient degradation of gluten by a prolyl endoprotease in a gastrointestinal model: implications for coeliac disease. Gut, Vol.57, No.1, (January 2008), pp.25-32, ISSN 1468-3288.

Morón, B., Cebolla, A., Manyani, H., Alvarez-Maqueda, M., Megías, M., Thomas, M. del C., López, M.C. \& Sousa, C. (2008a). Sensitive detection of cereal fractions that are toxic to celiac disease patients by using monoclonal antibodies to a main immunogenic wheat peptide. The American Journal of Clinical Nutrition, Vol.87, No:2, (February 2008), pp.405-414, ISSN 1938-3207.

Morón, B., Bethune, M.T., Comino, I., Manyani, H., Ferragud, M., López, M.C., Cebolla, A., Khosla, C. \& Sousa, C. (2008b). Toward the assessment of food toxicity for celiac patients: characterization of monoclonal antibodies to a main immunogenic gluten peptide. PloS One, Vol.3, No.5, (May 2008), pp.e2294, ISSN 1932-6203.

Nassef, H.M., Bermudo, Redondo, M.C., Ciclitira, P.J., Ellis, H.J., Fragoso, A. \& O'Sullivan, C.K. (2008). Electrochemical immunosensor for detection of celiac disease toxic gliadin in foodstuff. Analytical Chemistry, Vol.80, No.23, (December 2008), pp.9265-9271, ISSN 0003-2700.

Pulido, O., Gillespie, Z., Zarkadas, M., Dubois, S., Vavasour, E., Rashid, M., Switzer, C. \& Goderfroy, S.B. (2009). Introduction of oats in the diet of individuals with celiac disease: A systematic review, In: Advances in Food and Nutrition Research, Steve L. Taylor, pp.235-285, ISBN 978-0-12-374440-1, USA.

Shan, L., Molberg, Ø., Parrot, I., Hausch, F., Filiz, F., Gray, G.M., Sollid, L.M. \& Khosla, C. (2002) Structural basis for gluten intolerance in celiac sprue. Science, Vol.297, No.5590, (September 2002), pp. 2275-2279, ISSN 1095-9203.

Siegel, M., Bethune, M.T., Gass, J., Ehren, J., Xia, J., Johannsen, A., Stuge, T.B., Gray, G.M., Lee, P.P. \& Khosla C. (2006). Rational design of combination enzyme therapy for celiac sprue. Chemistry \& Biology, Vol.13, No.6, (June 2006), pp.649-658, ISSN 1074-5521.

Skerritt, J.H. \& Hill, A.S. (1991). Enzyme immunoassay for determination of gluten in foods: collaborative study. Journal -Association of Official Analytical Chemists. Vol.74, No.2, (March-April 1991), pp.257-264, ISSN 1060-3271.

Sollid, L.M. \& Khosla, C. (2005). Future therapeutic options for celiac disease. Nature Clinical Practice. Gastroenterology \& Hepatology, Vol.2, No.3, (March 2005), pp.140-147, ISSN 1743-4386.

Stepniak, D. \& Koning, F. (2006). Celiac disease-sandwiched between innate and adaptive immunity. Human Immunology, Vol.67, No.6, (June 2006), pp.460-468, ISSN 01988859. 
Thompson, T. \& Mendéz, E. (2008). Commercial assays to assess gluten content of glutenfree foods: why they are not created equal. Journal of the American Dietetic Association, Vol.108, No.10, (October 2008), pp.1682-1687, ISSN 0002-8223.

Valdés, I., García, E., Llorente, M. \& Méndez E. (2003). Innovative approach to low-level gluten determination in foods using a novel sandwich enzyme-linked immunosorbent assay protocol. European Journal Gastroenterology \& Hepatology, Vol.15, No.5, (May 2003), pp.465-474, ISSN 1473-5687. 
(C) 2012 The Author(s). Licensee IntechOpen. This is an open access article distributed under the terms of the Creative Commons Attribution 3.0 License, which permits unrestricted use, distribution, and reproduction in any medium, provided the original work is properly cited. 